\title{
The ecology of Staphylococcus species in the oral cavity
}

\author{
A. J. SMITH, M. S. JACKSON and J. BAGG \\ Infection Research Group, Glasgow Dental Hospital and School, 378 Sauchiehall Street, Glasgow G2 3JZ
}

\begin{abstract}
Whilst the diversity of organisms present in the oral cavity is well accepted, there remains considerable controversy as to whether Staphylococcus spp. play a role in the ecology of the normal oral flora. Surprisingly little detailed work has been performed on the quantitative and qualitative aspects of colonisation or infection either by coagulasenegative staphylococci (CNS) or $S$. aureus. The latter is especially interesting in the light of present difficulties in eradicating carriage of methicillin-resistant $S$. aureus (MRSA) from the oropharynx in affected individuals. This paper reviews the current knowledge of staphylococcal colonisation and infection of the oral cavity in health and disease. $S$. aureus has been isolated from a wide range of infective oral conditions, such as angular cheilitis and parotitis. More recently, a clinical condition classified as staphylococcal mucositis has emerged as a clinical problem in many debilitated elderly patients and those with oral Crohn's disease. Higher carriage rates of both CNS or S. aureus, or both, in patients prone to joint infections raises the interesting possibility of the oral cavity serving as a potential source for bacteraemic spread to compromised joint spaces. In conclusion, there is a surprising paucity of knowledge regarding the role of oral staphylococci in both health and disease. Further work in this area may lead to benefits, such as improved decolonisation regimens for eradication of MRSA and acknowledgement of the mouth as a source of bacteraemic staphylococci.
\end{abstract}

\section{Introduction}

Despite the extensive literature on Staphylococcus aureus and coagulase-negative staphylococci (CNS), relatively little attention has been paid to the oral cavity as a reservoir for these organisms. The oral flora contains $>300$ known species of bacteria in addition to numerous non-cultivable organisms which are being discovered as a result of molecular biological techniques [1]. Whilst the importance of staphylococci as medical pathogens has been recognised for many years, the presence of Staphylococcus species as a component of the resident oral flora is controversial but, surprisingly, there have been relatively few detailed studies of the distribution of staphylococci in the mouth. Some infections in the circum-oral region are caused, at least in part, by $S$. aureus. These include angular cheilitis [2], some endodontic infections [3-5], osteomyelitis of the jaw [6], parotitis $[7,8]$ and, more recently recognised, a form of oral mucositis in elderly, highly dependent patients receiving parenteral nutrition [9].

Received 8 Feb. 2001; accepted 1 June 2001.

Corresponding author: Dr A. J. Smith (e-mail: a.smith@ dental.gla.ac.uk).
Interestingly, there is now a growing body of evidence to suggest that staphylococci can be isolated frequently from the oral cavity of particular patient groups such as children [10], the elderly [9] and some groups with systemic disease such as the terminally ill [11], those with rheumatoid arthritis [12] and patients with haematological malignancies [13]. Of further concern is the observation that the oropharynx is frequently colonised with strains of methicillin-resistant S. aureus (MRSA) which may prove difficult to eradicate [14]. Therefore, it is apparent that the oral cavity may represent a hitherto poorly recognised reservoir of staphylococci, some of which may, under appropriate conditions, cause local or systemic infection. There is also the potential for dissemination of oral staphylococcal strains to re-colonise other body sites or as a source of cross-infection to other patients or staff. The aim of this review is to examine the current knowledge of the ecology of staphylococcal species in the oral cavity and their impact on systemic health.

\section{The normal oral flora}

The normal oral flora comprises a diverse group of micro-organisms, including bacteria, fungi, protozoa 
and possibly even viruses [15]. More than 300 species inhabit the oral cavity [1], of which about 30 are found routinely and account for the majority of the cultivable strains. These factors, together with the fact that the oral cavity has a wide range of sites with different environmental conditions, make the study of oral microbiology complex and difficult.

\section{Staphylococci in the healthy oral cavity}

There are several early qualitative reports of $S$. aureus isolated from the healthy oral cavity but detailed information on the intra-oral distribution of staphylococci is lacking. Most studies sample the oral cavity by use of swabs, rinses or plaque scrapings, although one group [16] found staphylococci in plaque from the fissures of teeth. Percival and colleagues [17] reported the isolation of staphylococci, albeit with low mean percentage counts, from $c .12 \%$ of supragingival plaque samples in 79 healthy individuals with ages ranging from 27 to 84 years. There were no clear age-related trends in the isolation frequency or proportions of staphylococci in this study. Another study [10] investigating oral staphylococcal carriage in 307 children aged $<1-5$ years attending a paedodontic department found that $84 \%$ carried staphylococcal species, $33 \%$ of which were $S$. aureus $(5 \%$ of the $S$. aureus isolates were MRSA). Of interest was the fact that $19 \%$ of the $S$. aureus isolates produced exfoliative toxin and $40 \%$ produced enterotoxin [10]. A more recent study [13] found that $64 \%$ of healthy children carried $S$. aureus in the oral cavity.

In studies of student populations, oral carriage rates of S. aureus have ranged from $17 \%$ [18] to $48 \%$ [19]. More recently, workers have revealed that between $94 \%$ and $100 \%$ of healthy adults had oral colonisation with Staphylococcus spp. [17, 20,21] and oral carriage of $S$. aureus ranged from $24 \%$ to $36 \%$ [20, 21]. The presence of prosthetic devices within the oral cavity, such as acrylic dentures, may encourage carriage of staphylococci [22]. In studies of denture-wearing patients, carriage rates of $S$. aureus varied from $23 \%$ to $48 \%$ $[23,24]$.

Staphylococci have been isolated from supragingival plaque (see Table 1 for details) $[16,25,26]$ and from subgingival plaque [27-34]. Relatively few plaque samples have been collected from non-diseased sites and, therefore, no definitive interpretation of the available qualitative and quantitative data for staphylococci in health is possible. The species of staphylococci most frequently reported from oral samples are $S$. epidermidis and $S$. aureus, but $S$. haemolyticus, $S$. hominis, S. warneri, S. capitis, S. saprophyticus, $S$. xylosus and $S$. simulans have also been reported $[32,35]$.

Most investigators employ selective agar (mannitol salt agar, MSA) to identify the presence of $S$. aureus from oral specimens. Very few studies report actual numbers $(\mathrm{cfu} / \mathrm{ml})$ of staphylococci in healthy or compromised patients, which makes comparison between different studies difficult. Furthermore, few longitudinal studies have been performed, so that there is little definitive evidence to confirm or refute the general impression that Staphylococcus spp. may be transitory members of the oral microflora.

\section{Staphylococci in oral disease}

Despite its pathogenic potential, $S$. aureus is only infrequently associated with acute dento-alveolar infections [36, 37]. Other oral infections from which $S$. aureus has been cultured include infected jaw cysts [38], oral mucosal lesions [23, 39] and denture-induced

Table 1. Summary of studies in which Staphylococcus spp. have been isolated from dental plaque

\begin{tabular}{|c|c|c|c|c|c|c|}
\hline $\begin{array}{l}\text { Patient } \\
\text { group }\end{array}$ & $\begin{array}{l}\text { Mean age } \\
\text { of patient } \\
\text { (years) }\end{array}$ & $\begin{array}{l}\text { Number of } \\
\text { patients } \\
\text { sampled }\end{array}$ & $\begin{array}{l}\text { Number } \\
\text { of sites } \\
\text { sampled }\end{array}$ & $\begin{array}{c}S . \text { aureus } \\
\text { isolation rate } \\
\text { n (\% isolation } \\
\text { frequency) }\end{array}$ & $\begin{array}{c}\text { CNS } \\
\mathrm{n}(\% \text { isolation } \\
\text { frequency) }\end{array}$ & Ref. no. \\
\hline Tooth fissures & NR & 10 & 1 & $1(10 \%)$ & $8(80 \%)$ & 16 \\
\hline Healthy dentate adults & 27 & 30 & 1 & $2(7 \%)$ & $3(10 \%)$ & 17 \\
\hline Healthy dentate adults & 50 & 23 & 1 & 0 & $1(4 \%)$ & 17 \\
\hline Healthy dentate adults & 73 & 16 & 1 & $1(6 \%)$ & $2(12 \%)$ & 17 \\
\hline Healthy dentate adults & 84 & 10 & 1 & 0 & $1(10 \%)$ & 17 \\
\hline Gingivitis & 39 & 18 & 1 & $9(50 \%)$ & NR & 32 \\
\hline Periodontal disease & $32-66$ & 21 & 1 & $11\left(52 \%^{*}\right)$ & $11\left(52 \%{ }^{*}\right)$ & 27 \\
\hline Periodontal disease & $40-49$ & 72 & 1 & 0 & $16(22 \%)$ & 28 \\
\hline $\begin{array}{l}\text { Advanced adult } \\
\text { periodontal disease }\end{array}$ & 50 & 506 & 3 & $253(50 \%)$ & NR & 32 \\
\hline $\begin{array}{l}\text { Adult periodontal } \\
\text { disease }\end{array}$ & 45 & 535 & 2 & $43(8 \%)$ & $289(54 \%)$ & 33 \\
\hline $\begin{array}{l}\text { Early onset } \\
\text { periodontal disease }\end{array}$ & 35 & 108 & 3 & $49(45 \%)$ & NR & 32 \\
\hline $\begin{array}{l}\text { Localised juvenile } \\
\text { periodontitis }\end{array}$ & 18 & 13 & 3 & $4(31 \%)$ & NR & 32 \\
\hline Failing dental implants & 58 & 13 & 3 & $9(69 \%)$ & NR & 32 \\
\hline
\end{tabular}

NR, not recorded.

*Staphylococci isolated but $S$. aureus isolation rate not specified. 
stomatitis [22, 40]. More usually, $S$. aureus infection is associated with angular cheilitis. Workers have found an isolation rate of $63 \%$ for $S$. aureus from this condition - usually in the presence of other microorganisms such as Candida albicans or Streptococcus pyogenes [41]. Angular cheilitis is thought to be due to a combination of ill-fitting dentures, nutritional deficiencies and infection by $S$. aureus or C. albicans, or both. Whilst there are few studies on the presence of Staphylococcus spp. in the healthy oral cavity, more has been reported from patients demonstrating ill health. In a study of 110 patients attending a dental hospital with a range of oral diseases [42], there was an observed prevalence of $S$. aureus in saliva of $21 \%$ and from gingival swabs of $11 \%$. Salivary carriage of $S$. aureus in a cohort of patients with reduced salivary flow rates attending an oral medicine clinic was found in $41 \%$ of patients with a range of concentrations from $3.7 \times 10^{1}$ to $5.2 \times 10^{3} \mathrm{cfu} / \mathrm{ml}$ [43].

Oral mucosal infection with $S$. aureus has recently been incriminated in a severe form of mucositis reported in some groups with systemic disease such as patients with oral Crohn's disease [44] and geriatric patients [9]. The case for $S$. aureus in the aetiology of oral mucositis is complicated by the complexity of the normal oral flora and by healthy carriage of $S$. aureus in some patient groups. However, both clinical and microbiological data lend support to this hypothesis. The clinical presentation of staphylococcal mucositis commonly takes the form of oral discomfort and panoral mucosal erythema which may progress to marked crusting and bleeding of the oral mucosa $[9,11,44]$. Treatment of this condition with appropriate antistaphylococcal agents leads to marked clinical im- provement $[9,44]$. The reason for the breakdown in colonisation of the oral mucosa is unclear, although in some groups of patients, notably elderly patients receiving parenteral nutrition and patients with advanced malignant disease, reduced salivary flow rate is an important risk factor. Saliva, in addition to its mechanical cleaning effects, also contains many antimicrobial factors, such as lysozyme and secretory IgA. An alternative hypothesis for the clinical presentation of staphylococcal mucositis includes colonisation by toxin-producing strains of $S$. aureus. In one study, three of five patients with mucositis were colonised by toxic-shock syndrome toxin (TSST)-1producing strains, suggesting that heavy colonisation of the oral cavity with toxin-producing strains may cause local mucosal damage [9].

In a study of children with haematological malignancies [13], only $6(5 \%)$ of the 120 children with haematological malignancy carried oral $S$. aureus compared with $64 \%$ of 25 healthy children. It seems likely that the lower levels of $S$. aureus from children with malignancies are a result of frequent antibiotic treatment. In the same study, a significantly smaller proportion of the children with malignant disease (37\%) carried CNS compared with the healthy control children (64\%), but levels of carriage are higher than previously reported (Tables 2 and 3 ).

Rams and colleagues [32] discovered that c. 50\% of periodontal lesions harboured staphylococci. Only low proportions $(<1 \%)$ of staphylococci were present in the cultivable subgingival flora in $95 \%$ of the patients studied. No significant differences were detected in the occurrence of $S$. aureus between patients with gingi-

Table 2. Summary of studies in which Staphylococcus spp. have been isolated from saliva or oral swabs in patients with systemic or oral disease

\begin{tabular}{|c|c|c|c|c|c|c|c|}
\hline $\begin{array}{l}\text { Patient } \\
\text { group }\end{array}$ & $\begin{array}{l}\text { Mean age } \\
\text { of patient } \\
\text { (years) }\end{array}$ & $\begin{array}{l}\text { Number of } \\
\text { patients } \\
\text { sampled }\end{array}$ & $\begin{array}{l}\text { Number } \\
\text { of sites } \\
\text { sampled }\end{array}$ & $\begin{array}{l}\text { Specimen(s) } \\
\text { collected }\end{array}$ & $\begin{array}{c}\text { S. aureus } \\
\text { isolation rate } \\
\text { n (\% isolation } \\
\text { frequency) }\end{array}$ & $\begin{array}{c}\text { CNS } \\
\mathrm{n}(\% \text { isolation } \\
\text { frequency })\end{array}$ & Ref. no. \\
\hline $\begin{array}{l}\text { Children with } \\
\text { neoplasia }\end{array}$ & 8 & 125 & 1 & Oral swab & $6(5 \%)$ & $46(37 \%)$ & 13 \\
\hline Adults with neoplasia & 69 & 197 & 1 & Saliva & $50(25 \%)$ & NR & 11 \\
\hline Rheumatoid arthritis & 59 & 111 & 4 & Saliva and oral swab & $16(14 \%)$ & 0 & 63 \\
\hline Rheumatoid arthritis & 60 & 25 & 2 & Saliva and oral swab & $14(56 \%)$ & $10(40 \%)$ & 20 \\
\hline Geriatric unit & 70 & 107 & 4 & Oral swab & $\begin{array}{c}20(19 \%) \\
(20 \text { MRSA })\end{array}$ & NR & 71 \\
\hline $\begin{array}{l}\text { Chronically ill and } \\
\text { elderly clinic }\end{array}$ & NR & 40 & 4 & Saliva and oral swabs & $12(30 \%)$ & NR & 42 \\
\hline $\begin{array}{l}\text { Xerostomia (out-patient } \\
\text { clinic) }\end{array}$ & NR & 75 & 1 & Saliva & $31(41 \%)$ & NR & 43 \\
\hline Mucositis & $68-87$ & 5 & 4 & Oral swabs & $5(100 \%)$ & NR & 9 \\
\hline $\begin{array}{l}\text { Dentate patients with } \\
\text { mucosal oral disease }\end{array}$ & $0-90$ & 155 & 1 & Curettings and swabs & $30(19 \%)$ & NR & 23 \\
\hline $\begin{array}{l}\text { Orofacial } \\
\text { granulomatosis and } \\
\text { Crohn's disease }\end{array}$ & NR & 450 & 1 & Oral rinse & $4(0.8 \%)$ & NR & 44 \\
\hline Denture stomatitis & $0-90$ & 116 & 1 & Curettings and swabs & $27(23 \%)$ & NR & 23 \\
\hline $\begin{array}{l}\text { Patients with oral } \\
\text { abscess/osteomyelitis }\end{array}$ & NR & 10 & 1 & Oral swab & $3(30 \%)$ & $7(70 \%)$ & 21 \\
\hline Dental out-patients & NR & 80 & 4 & Saliva and oral swabs & $40(50 \%)$ & NR & 42 \\
\hline Surgical in-patients & NR & 40 & 4 & Saliva and oral swabs & $13(33 \%)$ & NR & 42 \\
\hline
\end{tabular}

NR, not recorded. 
Table 3. Summary of studies in which Staphylococcus spp. have been isolated from saliva or oral swabs in healthy patients

\begin{tabular}{|c|c|c|c|c|c|c|c|}
\hline Patient group & $\begin{array}{l}\text { Mean age } \\
\text { of patient } \\
\text { (years) }\end{array}$ & $\begin{array}{l}\text { Number of } \\
\text { patients } \\
\text { sampled }\end{array}$ & $\begin{array}{l}\text { Number } \\
\text { of sites } \\
\text { sampled }\end{array}$ & $\begin{array}{l}\text { Specimen }(s) \\
\text { collected }\end{array}$ & $\begin{array}{c}S . \text { aureus } \\
\text { isolation rate } \\
\mathrm{n} \text { (\% isolation } \\
\text { frequency) }\end{array}$ & $\begin{array}{c}\mathrm{CNS} \\
\mathrm{n}(\% \text { isolation } \\
\text { frequency) }\end{array}$ & Ref. no. \\
\hline Healthy children & 11 & 25 & 1 & $\begin{array}{l}\text { Oral rinse and oral } \\
\text { swab }\end{array}$ & $16(64 \%)$ & $20(80 \%)$ & 13 \\
\hline Healthy children & $0-5$ & 307 & 1 & Tongue swab & $\begin{array}{c}100(33 \%) \\
(5 \text { MRSA })\end{array}$ & $157(51 \%)$ & 10 \\
\hline Healthy children & $7-8$ & 539 & 1 & Oral rinse & $\begin{array}{c}200(37 \%) \\
(4 \text { MRSA })\end{array}$ & NR & 72 \\
\hline Students & NR & 100 & 2 & Oral swab & $27(27 \%)$ & $69(69 \%)$ & 18 \\
\hline Dental students & NR & 70 & 2 & Saliva & $32(46 \%)$ & NR & 19 \\
\hline Healthy dentate adults & 27 & 30 & 1 & Saliva & $9(30 \%)$ & $9(30 \%)$ & 17 \\
\hline Healthy adults & 32 & 50 & 2 & Saliva and oral swab & $12(24 \%)$ & $35(70 \%)$ & 20 \\
\hline Healthy dentate adults & 50 & 23 & 1 & Saliva & $7(30 \%)$ & $7(30 \%)$ & 17 \\
\hline Healthy Adults & 56 & 83 & 4 & Saliva and oral swab & $3(4 \%)$ & 0 & 63 \\
\hline Healthy adults & NR & 22 & 1 & Oral swab & $8(36 \%)$ & $14(64 \%)$ & 21 \\
\hline $\begin{array}{l}\text { Healthy denture- } \\
\text { wearing adults }\end{array}$ & 65 & 29 & 2 & Oral swab & $\begin{array}{c}14(48 \%) \\
(3 \text { MRSA) }\end{array}$ & $3(10 \%)$ & 24 \\
\hline Healthy elderly & 83 & 27 & 4 & Oral swabs & $11(41 \%)$ & NR & 9 \\
\hline Healthy elderly & 82 & 25 & 2 & Saliva and oral swab & $9(36 \%)$ & $16(64 \%)$ & 20 \\
\hline Healthy dentate elderly & 73 & 16 & 1 & Saliva & $7(44 \%)$ & $7(44 \%)$ & 17 \\
\hline Healthy dentate elderly & 84 & 10 & 1 & Saliva & $3(30 \%)$ & $4(40 \%)$ & 17 \\
\hline
\end{tabular}

NR, not recorded.

vitis or other more destructive forms of periodontal disease. Some workers [45] have reported elevated proportions of $S$. xylosus in actively destructive periodontal disease that was non-responsive to treatment. Other workers have isolated staphylococci from periodontitis in healthy persons [46-48], those with diabetes mellitus [47] and acute periodontal abscesses in immunocompromised patients [49]. In early studies [50,51], cellular components of $S$. aureus were found in the subepithelial connective tissues of $47 \%$ of specimens of inflamed gingival tissue, but not in healthy gingival tissue. However, in cases of failing dental implants, a significant proportion (69\%) of the affected sites had high proportions of Staphylococcus spp. (15-100\% of total flora) in the associated dental plaque [52]. This association has not been confirmed in other studies [53].

\section{Oral staphylococci as a source of systemic infection}

Classically, the mouth is recognised as a source of bacteraemia in infective endocarditis, but in studies of organisms isolated from bacteraemia associated with dental procedures [54,55] $S$. aureus is infrequently detected. Nevertheless, there is an increasing number of reports suggesting that staphylococci from an oral source may cause infection at distant sites [56, 57]. For example, $S$. lugdenensis endocarditis has been reported after a tooth extraction [56]. These bactaeraemic episodes may assume greater significance in medically compromised patients. Oral infections have been associated with septicaemias among those with haematological malignancy $[35,58]$. CNS are frequently isolated from blood cultures in patients receiving treatment for malignant disease [35]. This is commonly a result of colonisation of venous access devices, but in some cases no such source of infection is present. The mouth has not been generally considered to play a role in such infections, but many patients receiving chemotherapeutic drug regimens develop severe oral ulceration (mucositis) as a result of the effect of these drugs on the oral mucosa [59]. Such ulceration provides a portal of entry for organisms in the oral flora, and has already been identified in relation to septicaemia caused by oral streptococci in children receiving treatment for leukaemia. This has been demonstrated more recently by a $S$. epidermidis and Strep. oralis bacteraemia in a bone marrow transplant patient [58]. Identical isolates, as analysed by pulsedfield gel electrophoresis (PFGE), of $S$. epidermidis were found in the mouth and bloodstream, but not at the site of venous access. In many patients with serious staphylococcal infections the original source of the organism is unknown, but the mouth has not usually been sought as a primary focus, as staphylococci are not considered part of the normal oral flora. There has been a long-standing debate over the role of oral micro-organisms in the aetiology of late prosthetic joint infections [60] and the possible need for antibiotic prophylaxis in such patients during dental treatment. Staphylococci are the most important cause of prosthetic joint infections. $S$. aureus is a significant pathogen in acute septic arthritis, affecting both native and prosthetic joints, whereas $S$. epidermidis is responsible for a large percentage of late or chronic infections [61]. Such joints are frequently placed in patients with rheumatoid arthritis and the possibility of a bacteraemia from an oral source resulting in a prosthetic joint infection should be of considerable interest. At present, the source of staphylococcal joint 
sepsis cannot be identified in up to $30 \%$ of cases [62] However, it has been reported [63] that individuals with rheumatoid arthritis had a higher prevalence of $S$. aureus in the oral cavity compared with gendermatched control subjects. A recent study [20] investigated oral carriage of staphylococci in patients with rheumatoid arthritis (Table 2) and showed that a significantly higher proportion $(56 \%)$ of these patients carried oral $S$. aureus than controls $(24 \%)(\mathrm{p}<0.05)$. This is unlikely to be an age-related effect, as there was no significant difference between colonisation rates for the two adult control groups $(p>0.05)$ and the rheumatoid arthritis patients were considerably younger than the healthy elderly individuals. It is well recognised that many patients with rheumatoid arthritis have a reduced salivary flow rate, and the dry mouth may result in significant changes to the oral flora [64]. The drug regimens used in the treatment of rheumatoid arthritis, many of which are immunosuppressive or cytotoxic, will also affect the mucosal immunity in the mouth and some (e.g., methotrexate) can cause oral ulceration, further enhancing the possibility of an oral source for staphylococcal joint sepsis. In a retrospective literature review of 23 cases of late prosthetic joint infection, in which it was suggested that the causal bacteria originated from the oral cavity as a result of treatment or infection, 10 cases $(43 \%)$ were caused by Staphylococcus spp., the most common being $S$. aureus (eight cases) [65].

\section{MRSA in the oral cavity}

The prevention of horizontal transmission of MRSA has become increasingly important as the prevalence of this pathogen increases. Oral carriage of MRSA may serve as a reservoir for re-colonisation of other body sites or for cross-infection to other patients or healthcare workers. At least two cases have been reported of cross-infection from a general dental practitioner to patients [66]. The practitioner had probably been colonised whilst a patient in hospital. Nursing homes are another important source of colonisation and infection and two cases of acute parotitis caused by MRSA in elderly patients have been described [67].

Attempts are frequently made to eradicate carriage of MRSA from either patients or medical staff colonised by this organism. However, clinical experience has shown that oropharyngeal carriage of MRSA can be difficult to eradicate [14]. Therefore, it is important that consideration be given to the oral cavity if eradication of colonisation by MRSA is clinically appropriate. Mupirocin is rarely effective alone in clearing oropharyngeal colonisation. Successful eradication of throat carriage of MRSA in a health-care worker has been achieved by the use of rifampicin and fusidic acid, in addition to topical mupirocin [68]. However, eradication of throat carriage of MRSA has been achieved with use of topical chlorhexidine $(0.2 \%)$ in addition to normal control measures of patient isolation, nasal mupirocin and chlorhexidine body washes [69]. Within the oral cavity MRSA may preferentially colonise denture surfaces. One group of workers [24] found $10 \%$ of unselected denture-wearing patients carrying MRSA on their dentures which proved difficult to eradicate with conventional denturecleaning agents. In a subsequent study, eradication of the long-term carriage of MRSA from denture-wearing patients was successful only after heat sterilising or remaking the dentures that had become persistently colonised by MRSA [70]. More recently, $19 \%$ of an elderly institutionalised veteran population were shown to be colonised by MRSA in the oral cavity, compared with a prevalence of $20 \%$ in the nares. Interestingly, $4 \%$ of subjects were culture positive for oral MRSA without evidence of nasal carriage [71].

Carriage of MRSA is not restricted to the chronically ill or institutionalised patients. One study [10] showed that a small proportion of children (5 from 307) carried MRSA, a larger proportion than a more recent study (4 from 539) [72]. Another group demonstrated that MRSA clones may colonise the oral cavity of healthy children for relatively long periods of time (5 years), challenging the hypothesis that staphylococci are transient members of the oral flora [73]. Surprisingly little work has been performed on factors affecting oropharyngeal colonisation by MRSA.

\section{Conclusion}

Our current knowledge of the role of staphylococci in the ecology of the oral flora in health and disease is incomplete. The majority of workers report the presence or absence of staphylococci using selective agar (MSA), which makes it difficult to compare isolation rates between different studies and different patient groups. Much of the data relates to mucosal swabs and salivary rinses with relatively little information linked specifically to plaque samples that have been both carefully collected and subsequently investigated by appropriate laboratory techniques. There is increasing interest in the oral ecology of opportunist micro-organisms, which may include MRSA. As micro-organisms growing in a biofilm such as plaque tend to be less susceptible to a range of antimicrobial agents, this could have important implications in diseases caused by these organisms, with regard to the creation of reservoirs of infection, re-infection and treatment failure due to antimicrobial resistance.

Future work in this area may provide clues for more successful eradication of carriage of MRSA strains. Advances in molecular microbiology may provide some interesting insights into the source of bacteraemic staphylococcal infection and these may challenge current concepts of antibiotic prophylaxis in groups of at-risk patients undergoing dental treatment. 
The results of this review clearly demonstrate that staphylococcal species can be frequently isolated in the oral flora of children and adults in both health and disease. Further longitudinal studies are required to establish whether this is a transient presence. This also implies that the oral cavity should be considered a potential source of infection for distant sites when other more obvious foci have been eliminated.

\section{References}

1. Wilson MJ, Weightman AJ, Wade WG. Applications of molecular ecology in the characterization of uncultured microorganisms associated with human disease. Rev Med Microbiol 1997; 8: 91-101.

2. MacFarlane TW, Helnarska SJ. The microbiology of angular cheilitis. Br Dent J 1976; 140: 403-406.

3. Kaufman AY, Henig EF. The microbiologic approach in endodontics. Oral Surg Oral Med Oral Pathol 1976; 42: $810-816$.

4. Tronstad L, Barnett F, Riso K, Slots J. Extraradicular endodontic infections. Endod Dent Traumatol 1987; 3: 86-90.

5. Wyman TP, Dowden WE, Langeland K. Staphylococcus aureus isolation from a clinically nonexposed root canal. J Endodont 1978; 4: 122-128.

6. Koorbusch GF, Fotos P, Goll KT. Retrospective assessment of osteomyelitis. Etiology, demographics, and management in 35 cases. Oral Surg Oral Med Oral Pathol 1992; 74: 149-154.

7. Goldberg MH. Infections of the salivary glands. In: Topazian RG, Goldberg MH (eds) Management of infections of the oral and maxillofacial regions. Philadelphia, WB Saunders. 1981: 293-311.

8. Lamey P-J, Boyle MA, MacFarlane TW, Samaranayake LP, Biol MI. Acute suppurative parotitis in outpatients: microbiological and posttreatment sialographic findings. Oral Surg Oral Med Oral Pathol 1987; 63: 37-41.

9. Bagg J, Sweeney MP, Harvey-Wood K, Wiggins A. Possible role of Staphylococcus aureus in severe oral mucositis among elderly dehydrated patients. Microb Ecol Health Dis 1995; 8: $51-56$.

10. Miyake Y, Iwai M, Sugai M, Miura K, Suginaka H, Nagasaka N. Incidence and characterization of Staphylococcus aureus from the tongues of children. J Dent Res 1991; 70: 1045-1047.

11. Jobbins J, Bagg J, Parsons K, Finlay I, Addy M, Newcombe RG. Oral carriage of yeasts, coliforms and staphylococci in patients with advanced malignant disease. J Oral Pathol Med 1992; 21: 305-308.

12. Jacobson JJ, Patel B, Asher G, Wooliscroft JO, Schaberg D. Oral staphylococcus in older subjects with rheumatoid arthritis. J Am Geriat Soc 1997; 45: 590-593.

13. Jackson MS, Bagg J, Kennedy H, Michie J. Staphylococci in the oral flora of healthy children and those receiving treatment for malignant disease. Microb Ecol Health Dis 2000; 12: $60-64$.

14. Working Party Report. Revised guidelines for the control of methicillin-resistant Staphylococcus aureus infection in hospital. J Hosp Infect 1998; 39: 253-290.

15. Marsh P, Martin MV. Oral microbiology, 4th edn. Oxford, Wright. 1999.

16. Theilade E, Fejerskov O, Karring T, Theilade J. Predominant cultivable microflora of human dental fissure plaque. Infect Immun 1982; 36: 977-982.

17. Percival RS, Challacombe SJ, Marsh PD. Age-related microbiological changes in the salivary and plaque microflora of healthy adults. J Med Microbiol 1991; 35: 5-11.

18. Murphy RA. Elastase production by oral staphylococci. J Dent Res 1974; 53: 832-834.

19. Knighton HT. Coagulase-positive staphylococci in oral and nasal areas of dental students: a four-year study. J Dent Res 1965; 44: 467-470.

20. Jackson MS, Bagg J, Gupta MN, Sturrock RD. Oral carriage of staphylococci in patients with rheumatoid arthritis. Rheumatology 1999; 38: 572-575.

21. Kim KJ, You YO, Kim ES et al. $\delta$-Hemolysin like gene of
Staphylococcus lugdenensis in acute oral infection have partial homology with $\delta$-hemolysin gene of Staphylococcus aureus. $J$ Oral Biol 1995; 19: 61-65.

22. Theilade E, Budtz-Jorgensen E. Predominant cultivable microflora of plaque on removable dentures in patients with denture induced stomatitis. Oral Microbiol Immunol 1988; 3: 8-13.

23. Dahlen G, Linde A, Moller AJR, Ohman A. A retrospective study of microbiologic samples from oral mucosal lesions. Oral Surg Oral Med Oral Pathol 1982; 53: 250-255.

24. Tawara Y, Honma K, Naito Y. Methicillin-resistant Staphylococcus aureus and Candida albicans on denture surfaces. Bull Tokyo Dent Coll 1996; 37: 119-128.

25. Gibbons RJ, Socransky SS, de Araujo WC, Van Houte J. Studies on the predominant cultivable microbiota of dental plaque. Arch Oral Biol 1964; 9: 365-370.

26. Piochi BJA, Zelante F. Contribution to the study of staphylococcus isolated from the mouth. III Staphylococcus isolated from dental plaque. Rev Fac Odont Sao Paulo 1995; 91-98.

27. Rams TE, Babalola OO, Slots J. Subgingival occurrence of enteric rods, yeasts and staphylococci after systemic doxycycline therapy. Oral Microbiol Immunol 1990; 5: 166-168.

28. Helovuo $H$, Hakkarainen $K$, Paunio $K$. Changes in the prevalence of subgingival enteric rods, staphylococci and yeasts after treatment with penicillin and erythromycin. Oral Microbiol Immunol 1993; 8: 75-79.

29. Gibbons RJ, Socransky SS, Sawyer S, Kapsimalis B, Macdonald JB. The microbiology of the gingival crevice area of man. II The predominant cultivable organisms. Arch Oral Biol 1963; 8: 281-289.

30. Sanchez-Cordero S, Hoffman H, Stahl SS. Occurrence of staphylococcus in periodontal pockets of diabetic and nondiabetic adults. J Periodontol 1979; 50: 109-113.

31. Moore WEC, Holdeman LU, Cato EP et al. Comparative bacteriology of juvenile periodontitis. Infect Immun 1985; 48: 507-519.

32. Rams TE, Feik D, Slots J. Staphylococci in human periodontal diseases. Oral Microbiol Immunol 1990; 5: 29-32.

33. Dahlen G, Wikstrom M. Occurrence of enteric rods, staphylococci and candida in subgingival samples. Oral Microbiol Immunol 1995; 10: 42-46.

34. Kamma JJ, Nakou M, Baehni PC. Clinical and microbiological characteristics of smokers with early onset periodontitis. $J$ Periodont Res 1999; 34: 25-33.

35. Jackson MS. Oral staphylococci in health and disease. FIBMS thesis, Institute of Biomedical Science. 1998.

36. Lewis MAO, MacFarlane TW, McGowan DA. A microbiology and clinical review of acute dentoalveolar abscess. $\mathrm{Br} \mathrm{J} \mathrm{Oral}$ Maxillofac Surg 1990; 28: 359-366.

37. Labriola JD, Mascaro J, Albert B. The microbiologic flora of orofacial abscesses. J Oral Maxillofac Surg 1983; 41: $711-714$.

38. Iatrou IA, Legakis N, Ioannidou E, Patrikiou A. Anaerobic bacteria in jaw cysts. Br J Oral Maxillofac Surg 1988; 26: 62-69.

39. Bergmann OJ. Oral infections and septicemia in immunocompromised patients with haematologic malignancies. J Clin Microbiol 1988; 26: 2105-2109.

40. Theilade E, Budtz-Jorgensen E, Thelaide J. Predominant cultivable microflora of plaque on removable dentures in patients with healthy oral mucosa. Arch Oral Biol 1983; 28: 675-680.

41. Öhman S-C, Dahlén G, Möller $\AA$, Öhman A. Angular cheilitis: a clinical and microbial study. J Oral Pathol 1986; 15: 213-217.

42. Kondell PA, Nord CE, Nordenram G. Characterization of Staphylococcus aureus isolates from oral surgical outpatients compared to isolates from hospitalized and non-hospitalized individuals. Int J Oral Surg 1984; 13: 416-422.

43. Samaranayake LP, MacFarlane TW, Lamey P-J, Ferguson MM A comparison of oral rinse and imprint sampling techniques for the detection of yeast, coliform and Staphylococcus aureus carriage in the oral cavity $J$ Oral Pathol 1986; 15: 386-388.

44. Gibson J, Wray D, Bagg J. Oral staphylococcal mucositis. A new clinical entity in orofacial granulomatosis and Crohn's disease. Oral Surg Med Pathol Oral Radiol Endod 2000; 89. $171-176$.

45. Socransky SS, Haffajee AD, Dzink JL. Relationship of subgingival microbial complexes to clinical features at the 
sampled sites. J Clin Periodontol 1988; 15: 440-444.

46. Moore WEC, Holdeman LV, Cato EP et al. Comparative bacteriology of juvenile periodontitis. Infect Immun 1985; 48: 507-519.

47. Sànchez-Codero S, Hoffman H, Stahl SS. Occurrence of staphylococcus in periodontal pockets of diabetic and nondiabetic adults. J Periodontol 1979; 50: 109-113.

48. Williams BL, Pantalone RM, Sherris JC. Subgingival flora and periodontitis. J Periodont Res 1976; 11: 1-18.

49. Peterson DE, Minah GE, Overholser CD et al. Microbiology of acute periodontal infection in myelosuppressed cancer patients. $J$ Clin Oncol 1987; 5: 1461-1468.

50. Tsutsui M, Utsumi N, Tsubakimoto K. Cellular components of staphylococci and streptococci in inflamed human gingiva. $J$ Dent Res 1968; 47: 663.

51. Takeuchi H, Sumitani M, Tsubakimoto K, Tsutsui M. Oral microorganisms in the gingiva of individuals with periodontal disease. J Dent Res 1974; 53: 132-136.

52. Slots J, Feik D, Rams TE. Age and sex relationships of superinfecting microorganisms in periodontitis patients. Oral Microbiol Immunol 1990; 5: 305-308.

53. Listgarten M, Lai CH. Comparative microbiological characteristics of failing implants and periodontally diseased teeth. $J$ Periodontol 1999; 70: 431-437.

54. Roberts GJ, Holzel HS, Sury MR, Simmons WA, Gardner P, Longhurst P. Dental bacteremia in children. Pediatr Cardiol 1997; 18: 24-27.

55. Lockhart PB. An analysis of bacteremias during dental extractions. A double-blind, placebo-controlled study of chlorhexidine. Arch Intern Med 1996; 156: 513-520.

56. Kralovic SM, Melin-Aldana H, Smith KK, Linnemann CC Staphylococcus lugdenensis endocarditis after tooth extraction. Clin Infect Dis 1995; 20: 715-716.

57. Etienne J, Fleurette J, Ninet JF, Favet P, Gruer LD. Staphylococcal endocarditis after dental extraction. Lancet 1986; 2: 511-512.

58. Kennedy HF, Morrison D, Kaufmann ME et al. Origins of Staphylococcus epidermidis and Streptococcus oralis causing bacteraemia in a bone marrow transplant patient. $J \mathrm{Med}$ Microbiol 2000; 49: 367-370.

59. Rosenberg SW. Oral complications of cancer chemotherapy: a review of 398 patients. J Oral Med 1986; 41: 93-97.
60. Bartzokas CA, Johnson R, Jane M, Martin MV, Pearce PK, Saw Y. Relation between mouth and haematogenous infection in total joint replacements. BMJ 1994; 309: 506-508.

61. An YH, Friedman RJ. Prevention of sepsis in total joint arthroplasty. J Hosp Infect 1996; 33: 93-108.

62. Kaandorp CJE, Dinant HJ, Van de Laar MAFJ, Moens HJB, Prins APA, Dijkmans BAC. Incidence and source of native and prosthetic joint infection: a community based prospective survey. Ann Rheum Dis 1997; 56: 470-475.

63. Jacobson JJ, Patel B, Asher G, Woolliscroft JO, Schaberg D. Oral staphylococcus in older subjects with rheumatoid arthritis. J Am Geriat Soc 1997; 45: 590-593.

64. MacFarlane TW. The oral ecology of patients with severe Sjögrens syndrome. Microbios 1984; 41: 99-106.

65. Thyne GM, Ferguson JW. Antibiotic prophylaxis during dental treatment in patients with prosthetic joints. J Bone Joint Surg B 1991; 73: 191-194.

66. Martin MV, Hardy P. Two cases of oral infection by methicillin-resistant Staphylococcus aureus. Br Dent J 1991; 170: $63-64$.

67. Rousseau P. Acute suppurative parotitis. J Am Geriat Soc 1991; 38: 897-898.

68. Lessing MPA, Jordens JZ, Bowler ICJ. When should healthcare workers be screened for methicillin-resistant Staphylococcus aureus? J Hosp Infect 1996; 34: 205-210.

69. Balfour A, Higgins J, Brown M, Gallacher G. Eradication of throat carriage of methicillin-resistant Staphylococcus aureus. $J$ Hosp Infect 1997; 35: 320-321.

70. Rossi T, Peltonen R, Laine J, Eerola E, Vuopio-Varkila J, Kotilainen P. Eradication of the long-term carriage of methicillin-resistant Stapylococcus aureus in patients wearing dentures: a follow-up of 10 patients. J Hosp Infect 1997; 34: $311-320$.

71. Owen MK. Prevalence of oral methicillin-resistant Staphylococcus aureus in an institutionalized veterans population. Spec Care Dentist 1994; 14: 75-79.

72. Millar MR, Walsh TR, Linton CJ et al. Carriage of antibioticresistant bacteria by healthy children. J Antimicrob Chemother 2001; 47: 605-610.

73. Suzuki J, Komatsuzawa H, Sugai M et al. A long-term survey of methicillin-resistant Staphylococcus aureus in the oral cavity of children. Microbiol Immunol 1997; 41: 681-686. 